\title{
Seakeeping performance of a rounded hull catamaran in waves using CFD approach
}

\author{
A. Fitriadhy*, N.S. Razali and N. AqilahMansor \\ Program of Maritime Technology, School of Ocean Engineering, \\ Universiti Malaysia Terengganu, Malaysia \\ Tel: +609-6683350 Fax: +6096683991 \\ *Corresponding author: naoe.afit@gmail.com
}

\begin{abstract}
Prediction of the seakeeping performance of a ship in the earlier ship's design step is necessary to ensure the safety of navigation during sailing. To accommodate such a demand, this research proposes to analyse the seakeeping performance of a rounded hull catamaran. The vertical motion of the catamaran including the heave and pitch motions were quantified by her Response of Amplitude Operator (RAO). The Computational Fluid Dynamic software was used to develop the model, where several effects of various Froude numbers, hull lateral separation ratios and wavelengths on the heave, and pitch motions of the rounded hull catamaran have been taken into account. The results revealed that the higher Froude number associated with less hull lateral separation ratio was proportional to the subsequent increase of her heave and pitch motions. In the case of $\lambda / L \leq 1.0$, the seakeeping quality of the rounded hull catamaran has been improved and presented in the form of a sufficient reduction of the heave and pitch motions. It is shown that the estimated seakeeping performance of the rounded hull catamaran greatly depends on the Froude numbers and magnitude of wavelength.
\end{abstract}

\section{INTRODUCTION}

A catamaran ship is one of the multi-hull vessel types that geometrically consist of two demi-hulls. This inherent configuration offers some advantages compared with monohull ship types in view of the design feasibility and its operation (Srinivas and Srinivas [1] Medaković et al. [2]; and Kenevissi et al. [3]. Large deck areas of around 20 to 40 per cent greater than a corresponding mono-hull have better stability which enhances seakeeping characteristics in moderate sea states as reported by Hadler et al. [4], Piscopo and Scamardella [5] and Varyani et al. [6]. In addition, Rollings [7] reported that catamaran ships deal with less resistance due to presence of the lower draft as compared to the monohull ship types. Dyachkov and Makov [8] reported that one of the drawbacks of the catamaran usage is its seakeeping qualities. Because of the narrow form of the hulls, the seakeeping qualities (heave and pitch motions) are the same as the monohull ship and maybe even worse $[9,10]$. Therefore, the analysis of the seakeeping performance in the initial stage of the design involving behaviour of the heave and pitch motions of the catamaran is necessary to be studied.

Since the last decades, several researchers have conducted the analysis of the seakeeping performance of ships using theoretical and experimental approaches. Theoretically, the strip theory methods have been employed to investigate the 
seakeeping qualities of the catamaran [4]; [11]; [12]; [13]; [14]; [15] and [16]. Castiglione et al. [17] conducted a numerical study on the seakeeping characteristics of a high speed multi-hull vessel in high sea states. In addition, experimental models were tested on the seakeeping characteristics of wave-piercing catamarans in various wave headings and wave heights [18]; [19] and [20]. Begovic et al. [21] experimentally evaluated the effect of deadrise angle variations along the hull length on seakeeping characteristics and chose regular wave tests to get a better insight on motion and acceleration properties connected with warped hull forms. In addition, Bouscasse et al. [22], Kim et al. [23] and Diez et al. [24] experimentally studied a fast catamaran in both regular and irregular waves to assess the nonlinear effects into her hull motions. Similar work has been done by Bruzzone et al. [25], where the heave and pitch motions behaviour of the catamaran in regular waves were assessed. In particular; however, this approach is relatively expensive, time-consuming, and even impractical for various seakeeping test configurations. It became obvious that a reliable Computational Fluid Dynamic (CFD) approach has become necessary at gaining more accurate predictions of the seakeeping performance of the catamaran.

This paper presents a CFD simulation approach to analyse the seakeeping performance of a rounded hull form of a catamaran in regular waves. Here, the commercial CFD software so-called the NUMECA Fine ${ }^{\mathrm{TM}} / \mathrm{Marine}$ v3.1-1 was utilised by applying the incompressible unsteady Reynolds Averaged Navier Stokes Equation (RANSE). This RANSE and continuity equations were discretised by the finite volume method based on Volume of Fluid (VOF) to deal with the nonlinear free surface. In addition, the computational domain with adequate numbers of grid meshes of the catamaran has been carefully determined before simulations. Basically, this was solved by means of a mesh independent study to estimate the optimal domain discretisation. Several parameters such as various Froude numbers, wavelengths, and S/L ratios were taken into account in the computational simulation. The results were discussed to analyse their effects on the heave and pitch motions of the rounded hull catamaran, with the purpose of quantifying her seakeeping quality.

\section{Governing Equation}

\section{METHODS AND MATERIALS}

The CFD flow solver on NUMECA FINE ${ }^{\mathrm{TM}}$ /Marine 3.1-1 was based on the incompressible unsteady RANSE in which the solver applied the finite volume method to build the spatial discretisation of the transport equations. In addition, the velocity field was obtained from the momentum equations while the pressure field was extracted from the mass conservation constraint or continuity equation and transformed into a pressure equation. Furthermore, the nonlinear free surface flow was treated as the interface between air and water, which was assumed to be incompressible and isotropic Newtonian fluid.

\section{Conservation Equations}

In the multi-phase continuum, considering the incompressible flow of viscous fluid under isothermal conditions; mass, momentum, and volume fraction conservation equations can be expressed as (using the generalised form of Gauss' theorem [26]

$$
\frac{\partial}{\partial_{t}} \int_{S} \rho\left(\vec{U}-\vec{U}_{d}\right) \cdot \vec{n} d S=0
$$




$$
\begin{gathered}
\frac{\partial}{\partial_{t}} \int_{V} \rho U_{i} d V+\int_{S} \rho U_{i}\left(\vec{U}-\vec{U}_{d}\right) \cdot \vec{n} d S=\int_{S}\left(\tau_{i j} I_{j}-p I_{i}\right) \cdot \vec{n} d S+\int_{V} \rho g_{i} d V \\
\frac{\partial}{\partial_{t}} \int_{V} c_{i} d V+c_{i}\left(\vec{U}-\vec{U}_{d}\right) \cdot \vec{n} d S=0
\end{gathered}
$$

where $V$ is the control volume bounded by the closed surface $\mathrm{S}$ with a unit normal vector $\vec{n}$ directed outward that moves at the velocity $\vec{U}_{d}$ with a unit normal vector $\vec{n}$. The notations of $\vec{U}$ and $p$ represent the velocity and pressure fields, respectively. $\tau_{i j}$ and $g_{i}$ define the components of the viscous stress tensor and gravity vector, respectively; whereas $I_{j}$ is a vector whose components vanish except for the component $j$ which is equal to unity. $c_{i}$ is the $i^{t h}$ volume fraction for fluid $i$ used to distinguish the presence $\left(c_{i}=1\right)$ or the absence $\left(c_{i}=0\right)$ of $i^{\text {th }}$ fluid. Since the volume fraction between 0 and 1 indicates the presence of a mixture, the value of $1 / 2$ is selected as a definition of the interface.

\section{Turbulence Model}

In the case of a basic computation for turbulent conditions, we proposed the SST $k-$ $\omega$ (SST for shear-stress transport) model, which is available inside the ISIS-CFD solver code, where $k$ is the turbulent kinetic energy and $\omega$ is the specific dissipation rate. Menter [27], Menter [28], Menter [29] and Menter [30] reported that the SST $k-$ $\omega$ model combines several desirable elements of existing two-equation models. The two major features of this model are the zonal blending of model coefficients and a limitation on the growth of the eddy viscosity in rapidly strained flows. Spalart and Allmaras [31] and Baldwin and Barth [32] highlighted that the SST $k-\omega$ model here is set to improve the predictions obtained with algebraic mixing-length models to develop a local model for complex flows and provide a simpler alternative to twoequation turbulence models. This means that this turbulent model improves the prediction of flows with strong adverse pressure gradients and separation.

The two transport equations of the model are defined below with a blending function $F_{1}$ for the model coefficients of the original $\omega$ and $\varepsilon$ model equations and written as:

$$
\begin{array}{r}
\frac{\partial \rho K}{\partial t}+\frac{\partial}{\partial x_{j}}\left(\rho U_{j} K-\left(\mu+\sigma_{k} \mu_{t}\right) \frac{\partial K}{\partial x_{j}}\right)=\tau_{i j} S_{i j}-\beta^{*} \rho \omega K \\
\frac{\partial \rho \omega}{\partial t}+\frac{\partial}{\partial x_{j}}\left(\rho U_{j} \omega-\left(\mu+\sigma_{\omega} \mu_{t}\right) \frac{\partial \omega}{\partial x_{j}}\right)=P_{\omega}-\beta \rho \omega^{2}+2\left(1-F_{1}\right) \frac{\rho \sigma_{\omega 2}}{\omega} \frac{\partial K}{\partial x_{j}} \frac{\partial \omega}{\partial x_{j}}
\end{array}
$$

where the last source term of Eq. (5) represents the cross-diffusion term that appears in the transformed $\omega$-equation from the original $\varepsilon$-equation. Menter and Rumsey [33] noted that the production term of $\omega$ is sometimes approximated as proportional to the absolute value of vorticity:

$$
P_{\omega}=2 \gamma \rho\left(S_{i j}-\frac{\omega S_{n n} \delta_{i j}}{3}\right) S_{i j} \cong \gamma \rho \Omega^{2}
$$


The auxiliary blending function $F_{l}$ designed to blend the model coefficients of the original $\mathrm{k}-\omega$ model in boundary layer zones with the transformed $\mathrm{k}-\varepsilon$ model in free-shear layer and free-stream zones is defined as follows [26].

$$
F_{1}=\max \left\{\left[\min \left\{\max \left\{\frac{\sqrt{K}}{0.09 d \omega}, \frac{500 \mu}{\rho d^{2} \omega}\right\}, \frac{4 \varnothing \sigma_{\omega 2} k}{C D_{k \omega} d^{2}}\right\}\right]^{4}\right\}
$$

where $C D_{k \omega}=\max \left\{\frac{2 \rho \sigma_{\omega 2}}{\omega} \frac{\partial K}{\partial X_{J}} \frac{\partial \omega}{\partial X_{J}}, 10^{-20}\right\}$. Here, $C D_{k \omega}$ is the cross-diffusion in the $\mathrm{k}$ $-\omega$ model.

It should be noted here that when calculating turbulence quantities, it is important to consider an appropriate cell meshing size [34]. This can be explained by the fact that during computations using the Navier-Stokes equations, the boundary layer near a solid wall contains high gradients. Here, an appropriate estimation of the cell meshing size $y_{\text {wall }}$ for Navier-Stokes simulations including turbulence depends on the local Reynolds number, which is computed based on the wall variable $y^{+}$. Referring to [26], the value of $y^{+}$associated with the first node near the wall will be referred to as $y_{1}^{+}$, where the equation of $y_{1}^{+}$can be written as:

$$
y_{1}^{+}=\frac{\rho u_{\tau} y_{\text {wall }}}{\mu}
$$

where $u_{\tau}$ is the friction velocity, $u_{\tau}=\sqrt{\frac{\tau_{\text {wall }}}{\rho}}=\sqrt{\frac{1}{2} \rho\left(V_{\text {ref }}\right)^{2} C_{f}}$. It is clear that the value of $y_{\text {wall }}$ depends on the value of $y_{1}^{+}$.

In addition, the estimation for $y_{\text {wall }}$ as a function of a desired $y_{1}^{+}$value is obtained using a truncated series solution of the Blasius equation as written in Eq. (9).

$$
y_{\text {wall }}=6\left(V_{\text {ref }} / v\right)^{-7 / 8}\left(L_{\text {ref }} / 2\right)^{1 / 8} y_{1}^{+}
$$

Note that the reference velocity, $V_{\text {ref }}$, can be taken from the body velocity. The reference length, $L_{r e f}$, should be based on the body length since an estimation of the boundary layer thickness is implied in this calculation. For instance, in the case of a marine simulation, one could use the boat length, or the so-called length between perpendiculars, as the reference length. This refers to the length of a vessel along the waterline from the forward surface of the stem, or the main bow perpendicular member to the after surface of the stern-post or main stern perpendicular member.

\section{Heave and Pitch Motion}

The degree of freedom (D.O.F) represents the possible translations and rotation of the body. The heave and pitch motions are noted as the translation and rotation, respectively along the $\mathrm{X}, \mathrm{Y}$, and $\mathrm{Z}$-axes that define the behaviour of the catamaran under sailing. The coupled equation of heave and pitch motions are solved in the time domain for regular waves. These equations are demonstrated as follows:

$$
\begin{aligned}
& \left(M+A_{33}\right) \frac{d^{2} \eta_{3}}{d t^{2}}+B_{33} \frac{d \eta_{3}}{d t}+\mathrm{C}_{33} \eta_{3}+\mathrm{A}_{35} \frac{d^{2} \eta_{5}}{d t^{2}}+B_{35} \frac{d \eta_{5}}{d t}+\mathrm{C}_{35} \eta_{5}=F_{3} \\
& A_{53} \frac{d^{2} \eta_{3}}{d t^{2}}+B_{53} \frac{d \eta_{3}}{d t}+\mathrm{C}_{53} \eta_{3}+\left(\mathrm{I}_{55}+\mathrm{A}_{35}\right) \frac{d^{2} \eta_{5}}{d t^{2}}+B_{35} \frac{d \eta_{5}}{d t}+\mathrm{C}_{55} \eta_{5}=F_{5}
\end{aligned}
$$


In these equations, $\mathrm{M}$ is the mass of the ship, $\mathrm{I}_{55}$ is the moment of inertia and $\mathrm{A}_{\mathrm{ij}}, \mathrm{B}_{\mathrm{ij}}$ and $\mathrm{C}_{\mathrm{ij}}$ are the coefficients of added mass, the damping, and restoring coefficients, respectively. Also, $\mathrm{F}_{3}$ and $\mathrm{F}_{5}$ are the vertical forces and longitudinal moment on the ship, respectively [35].

\section{Simulation Condition \\ Ship Particulars}

In the computational simulation, the principal dimension of the rounded hull catamaran composed of two demi-hulls is clearly presented in Table 1.

Table 1. Principal dimension of a rounded hull catamaran model.

\begin{tabular}{lcc}
\hline \multicolumn{1}{c}{ Description } & Demi-hull & Catamaran \\
\hline Length, $(\mathrm{m})$ & 1.372 & 1.372 \\
Breadth, $(\mathrm{m})$ & 0.123 & - \\
Draught, $(\mathrm{m})$ & 0.078 & 0.078 \\
Wetted surface area, WSA, $\left(\mathrm{m}^{2}\right)$ & 0.2559 & 0.512 \\
Volume, $\left(\mathrm{m}^{3}\right)$ & 0.0072 & 0.0144 \\
Displacement, $(\mathrm{kg})$ & 7.222 & 14.444 \\
Vertical center of buoyancy, $(\mathrm{m})$ & 0.049 & 0.049 \\
\hline
\end{tabular}

\section{Simulation Parameter}

Referring to Figure 1, several parametric studies such as effects of the lateral separation length ratio $(\mathrm{S} / \mathrm{L})$ and various ratios of wavelengths with respect to length of the catamaran $(\lambda / \mathrm{L})$ with the range of 0.25 to 3.0 associated with various ranges of Froude number $(F r)$ from 0.19 to 0.66 were employed in the simulation. The details of simulation parameters are completely summarised in Table 2.

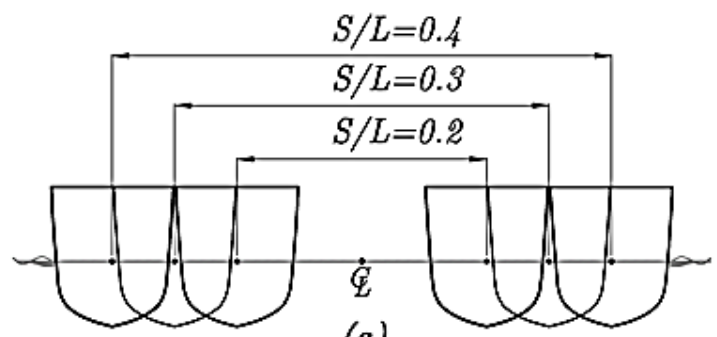

(a)

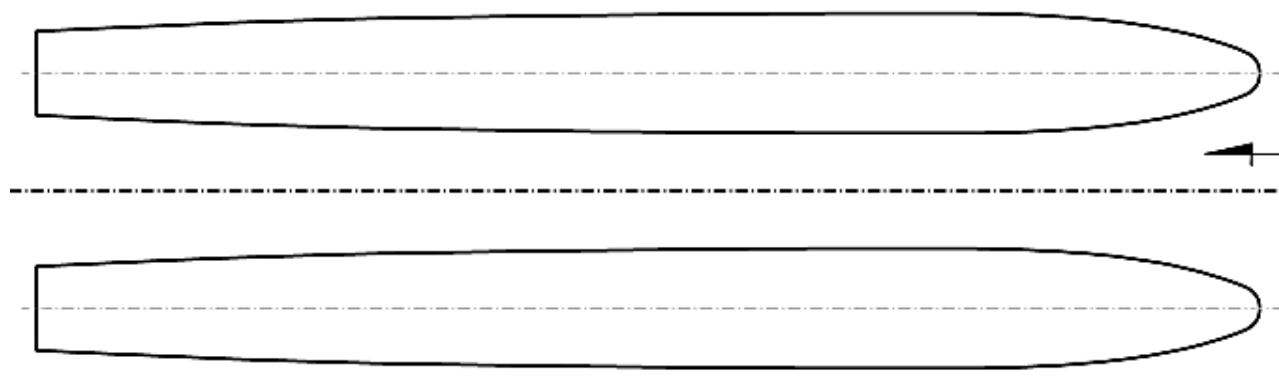

Figure 1. Several parametric studies on predicting seakeeping performance of a rounded catamaran model. 
Table 2. Matrix of computational simulation.

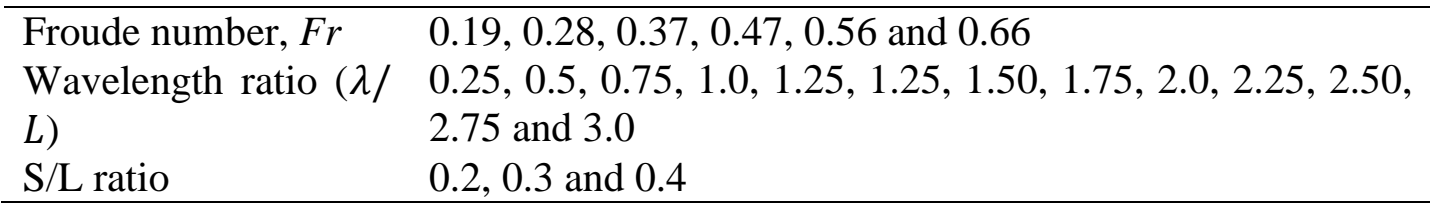

\section{Computational Domain and Meshing Generation}

The computational domain of the catamaran's hull used the unstructured hexahedral meshes as shown in Figure 2. There are extra local refinements of mesh added around the free surface to capture the waves generated by the catamaran's hull during computation. The local box refinement was also employed surrounding the global meshed computational domain and the maximum number of the local box refinement was set to be the same as the maximum global number of refinement which is 12 . Besides, another triangular-like surface was also added, which purpose was to capture the effective area in both $\mathrm{x}$ and $\mathrm{y}$ directions where the Kelvin waves will appear.

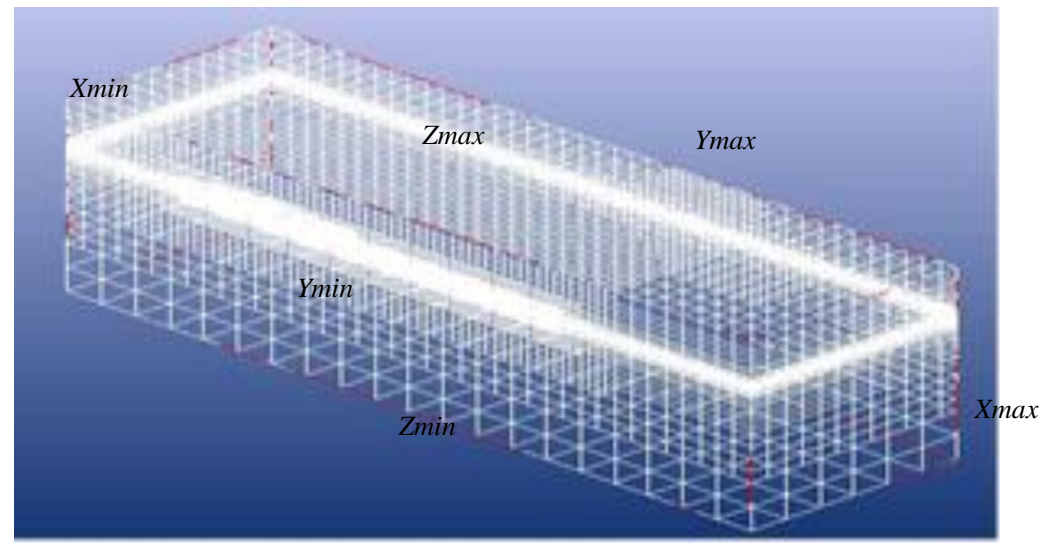

Figure 2. Mesh generation of catamaran.

Based on Table 3, the external (EXT) boundary type condition was assigned to treat velocity and pressure conditions. The boundary condition for the top of the patches domain was set as 'prescribed pressure'. In this setting, the pressure was imposed during the initialisation of the computation, where the updated hydrostatic pressure was then applied. This means that the pressure was not constantly 0 (zero) during the computation but it dynamically updated due to the cell mesh moving vertically towards the free surface position. The boundary conditions for the rounded catamaran surfaces were assigned as solid patches, where a wall-function condition was employed to these surfaces.

In this computational simulation, the average duration of every simulation was about 70 to 80 hours ( 4 parallel computations with $\Delta \mathrm{t}=0.001 \mathrm{~s}$ ) on a HP Z820 Workstation PC with processor Intel(R) Xeon(R) CPU ES-2690 v2 @ $3.00 \mathrm{GHz}$ (2 Processors) associated with the installed memory (RAM) of 32.0 GB and 64-bit Operating System. Referring to the mesh independent study results, the initial cell meshing of 960 with the total number of cell meshing of 2,284,082 have been selected in all computational simulations of the symmetrical catamaran model with reasonable accuracy of the CFD solution [36]. In the final stage of the CFD simulation, the CF 
View package software was used to visualise the wave pattern/ free surface elevation for all various configurations of the symmetrical and the staggered catamaran as displayed in Figure 3.

Table 3. Computational domain and boundary setting.

\begin{tabular}{lccc}
\hline \multicolumn{1}{c}{ Description } & $\begin{array}{c}\text { Distance with respect } \\
\text { to origin point }\end{array}$ & Type & Condition \\
\hline$X \min$ (Inlet) & $1.0 L_{m h}$ & EXT & Far field \\
$X \max$ (Outlet) & $3.0 L_{m h}$ & EXT & Far field \\
$Z \min$ (Bottom) & $1.5 L_{m h}$ & EXT & Prescribed pressure \\
$Z \max$ (Top) & $0.5 L_{m h}$ & EXT & Prescribed pressure \\
$Y \min$ (Side) & $1.5 L_{m h}$ & EXT & Far field \\
$Y \max$ (Side) & $1.5 L_{m h}$ & EXT & Far field \\
\hline
\end{tabular}

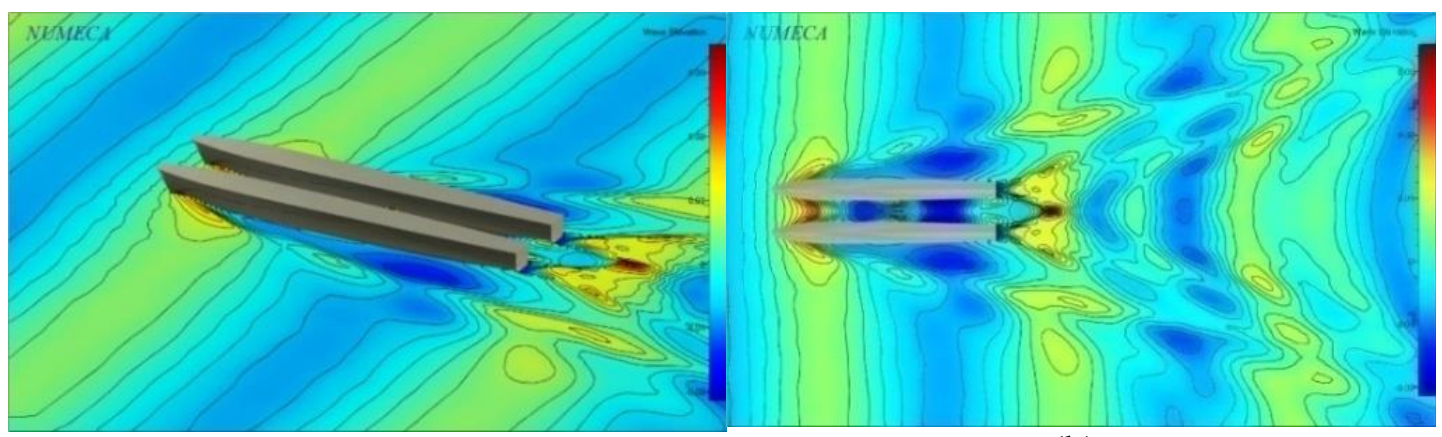

(a)

(b)

Figure 3. CFD visualisation; (a) perspective view, (b) plan view, where $F r=0.28$, $\mathrm{S} / \mathrm{L}=0.2, \lambda / \mathrm{L}=1.0$ and $\mathrm{H}_{\mathrm{w}} / \mathrm{L}=0.027$

\section{RESULTS AND DISCUSSION}

Referring to Figure 3, the CFD simulations on predicting the seakeeping performance on the rounded hull catamaran have been successfully carried out at various Froude numbers, $S / L$ ratios and $\lambda / L$ ratios. Effects of the parameter studies are presented through assessing the magnitude of the heave and pitch motions of the rounded hull catamaran. The simulation results are appropriately discussed in Figures 4 to 9.

\section{Effect of Froude Number (Fr)}

Referring to Figure 4, the increase of Froude number till up to 0.47 was proportional with the increase of the heave motions of the catamaran. It should be noted that the heave motion of the catamaran model significantly increased from $0.0063 \mathrm{~m}$ to 0.0154 $\mathrm{m}$ as Fr increased from 0.37 to 0.47 . Although the pitch motion decreased from $4.31^{\circ}$ to $3.28^{\circ}$, this condition was prone to degrade the seakeeping performance of the catamaran due to the vigorous heave motion responses. This could be explained by the fact that the increase of Froude number at 0.47 caused the catamaran to be relatively faster than the elevation of the incoming waves (red colour). As a result, the effects of resonance and exciting forces due to this incoming wave resulted in the large heave motion response of the catamaran (see Figure 5). Furthermore, the heave motion of 
the catamaran decreased at $\mathrm{Fr}=0.56$, which then inversely increased as well as Fr rose up to 0.66 . In the case of $\mathrm{Fr} \geq 0.37$, the heave and pitch motions of the rounded hull catamaran tended to gradually increase, indicated by the proportional increase of the free surface elevation (red colour). The visualisation of the free surface elevation of the rounded hull catamaran in waves associated with the various Froude numbers are appropriately displayed in Figure 5.
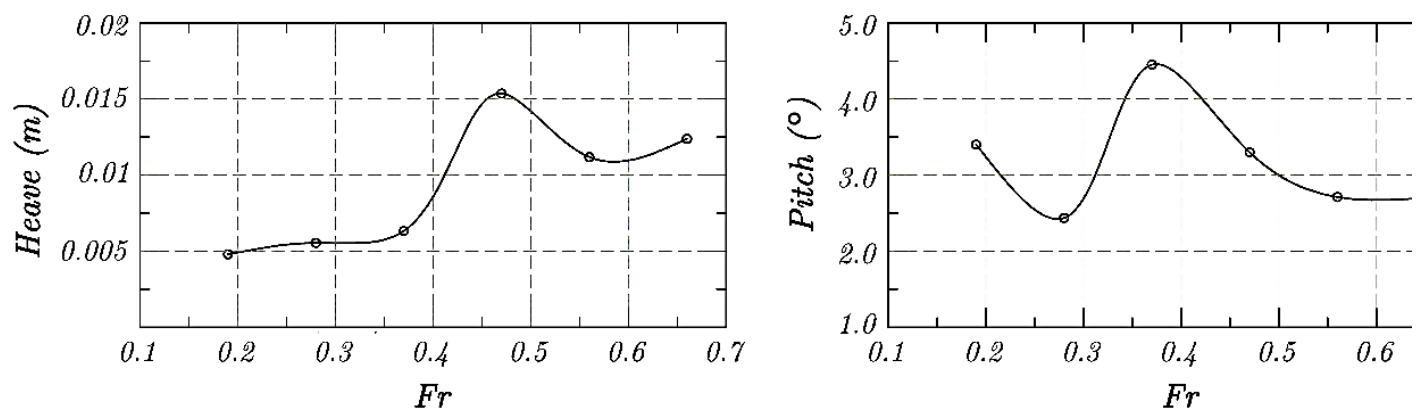

Figure 4. Motion of heave and pitch motions behaviour at various Froude number, $\mathrm{S} / \mathrm{L}=0.2, \lambda / \mathrm{L}=1.0$ and $\mathrm{H}_{\mathrm{w}} / \mathrm{L}=0.027$

Table 4. Behaviour of heave and pitch motions at various Froude numbers.

\begin{tabular}{cccc}
\hline S/L & $\begin{array}{c}\text { Froude No, } \\
F r\end{array}$ & Heave motion $(\mathrm{m})$ & Pitch motion $\left({ }^{\circ}\right)$ \\
\hline \multirow{4}{*}{0.2} & 0.19 & 0.0048 & 3.41 \\
& 0.28 & 0.0055 & 2.42 \\
& 0.37 & 0.0063 & 4.31 \\
& 0.47 & 0.0154 & 3.34 \\
& 0.56 & 0.0112 & 2.74 \\
& 0.66 & 0.0124 & 2.73 \\
\hline
\end{tabular}

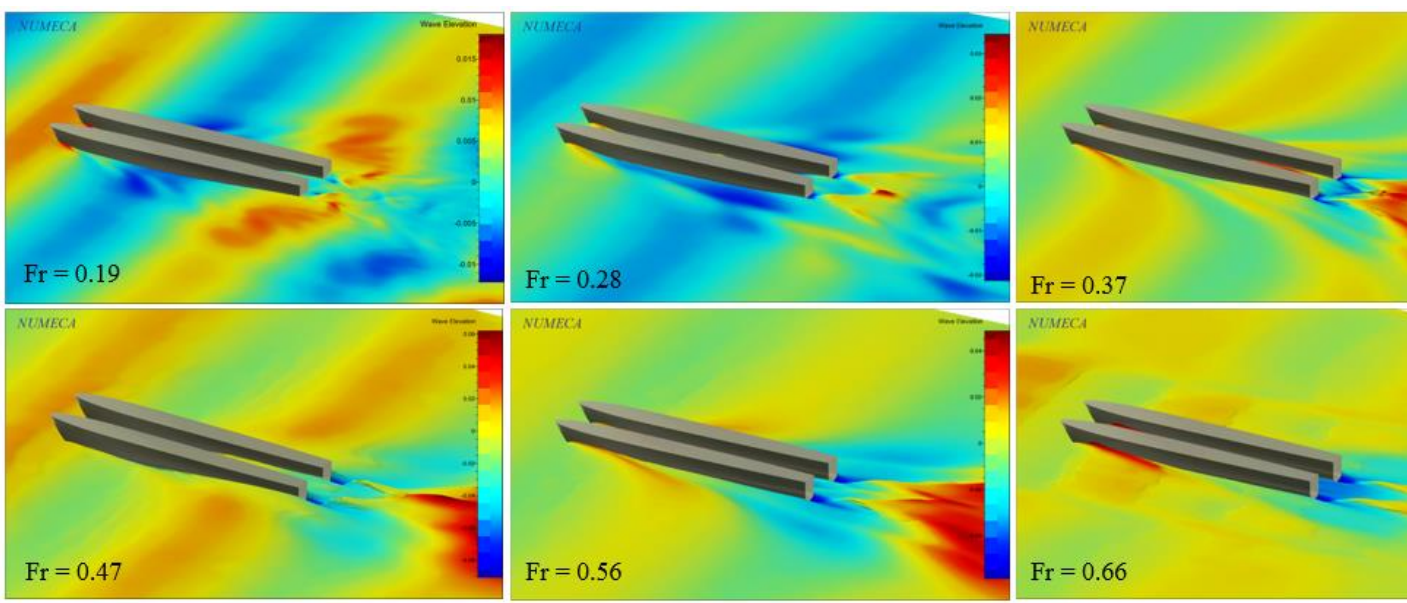

Figure 5.Wave pattern characteristics of catamaran at various Froude numbers with $\mathrm{S} / \mathrm{L}=0.2, \lambda / \mathrm{L}=1.0$ and $\mathrm{H}_{\mathrm{w}} / \mathrm{L}=0.027$. 


\section{Effect of Various Ratios of Wavelengths $(\lambda / L)$}

The characteristics for the heave and pitch motions of the rounded hull catamaran are shown in Figure 6. For the short wavelength condition, the motion amplitude was very small compared to others but it was confirmed that the periodic oscillation of the force resulted from wave reflection that occurred in both hull forms [37]. Upon increasing $\lambda / L$ from 0.25 to 1.75 , the results were considered to have sufficient effect, where the magnitude of the heave motion increased by $158 \%$ (Table 5); however, the pitch motion of the rounded hull catamaran subsequently increased up to $73.3 \%$ as $\lambda / L$ increased from 0.25 to 1.5 . This possibly occurred due to the vertical motion at the bow region of the catamaran which became relatively more stiff in motions [38]. Similar to what was conducted by [4], it was generally concluded that the rounded hull catamaran was liable to have vigorous vertical motion responses; both of the heave and pitch motions within the range of $1.5 \leq \lambda / L \leq 1.75$. Consequently, these unfavourable motions led to degrade the seakeeping qualities. In addition, the effect of the increase of wavelength was relatively small upon increasing the further ratio of $\lambda / L>2.0$. In this case, nonlinear effects play a role for wavelengths comparable or larger than the ship length. As displayed in Figure 7, the possible reason is that when the value of $\lambda / L$ became larger, the relative vertical motions of the catamaran with respect to the incoming waves dropped to negligibly smaller. In other words, the ship behaved like a cork floating in the water.
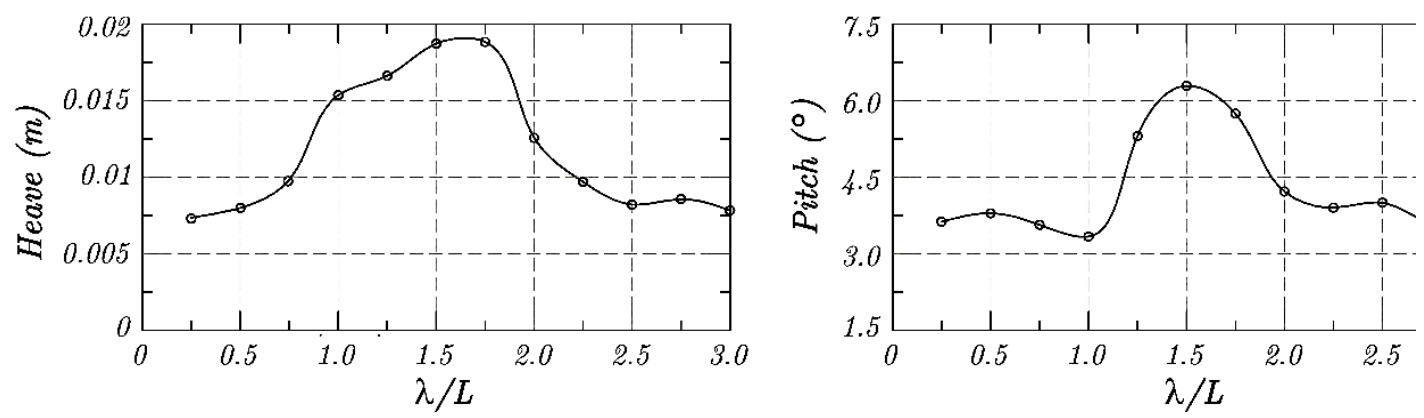

Figure 6. Heave and pitch motions behaviour at various wavelengths $(\lambda / L)$, $\mathrm{S} / \mathrm{L}=0.2, \mathrm{H}_{\mathrm{w}} / \mathrm{L}=0.027$ and $F r=0.47$

Table 5. Behaviour of heave and pitch motions at various ratios of $\lambda / \mathrm{L}$.

\begin{tabular}{ccc}
\hline Ratios of $\lambda / \mathrm{L}$ & Heave motion $(\mathrm{m})$ & Pitch motion $\left(^{\circ}\right)$ \\
\hline 0.25 & 0.0073 & 3.63 \\
0.5 & 0.008 & 3.79 \\
0.75 & 0.0097 & 3.57 \\
1.0 & 0.0154 & 3.34 \\
1.25 & 0.0166 & 5.31 \\
1.5 & 0.0188 & 6.29 \\
1.75 & 0.0189 & 5.75 \\
2.0 & 0.0126 & 4.22 \\
2.25 & 0.0097 & 3.91 \\
2.5 & 0.0082 & 4.01 \\
2.75 & 0.0086 & 3.59 \\
3.0 & 0.0073 & 1.66 \\
\hline
\end{tabular}




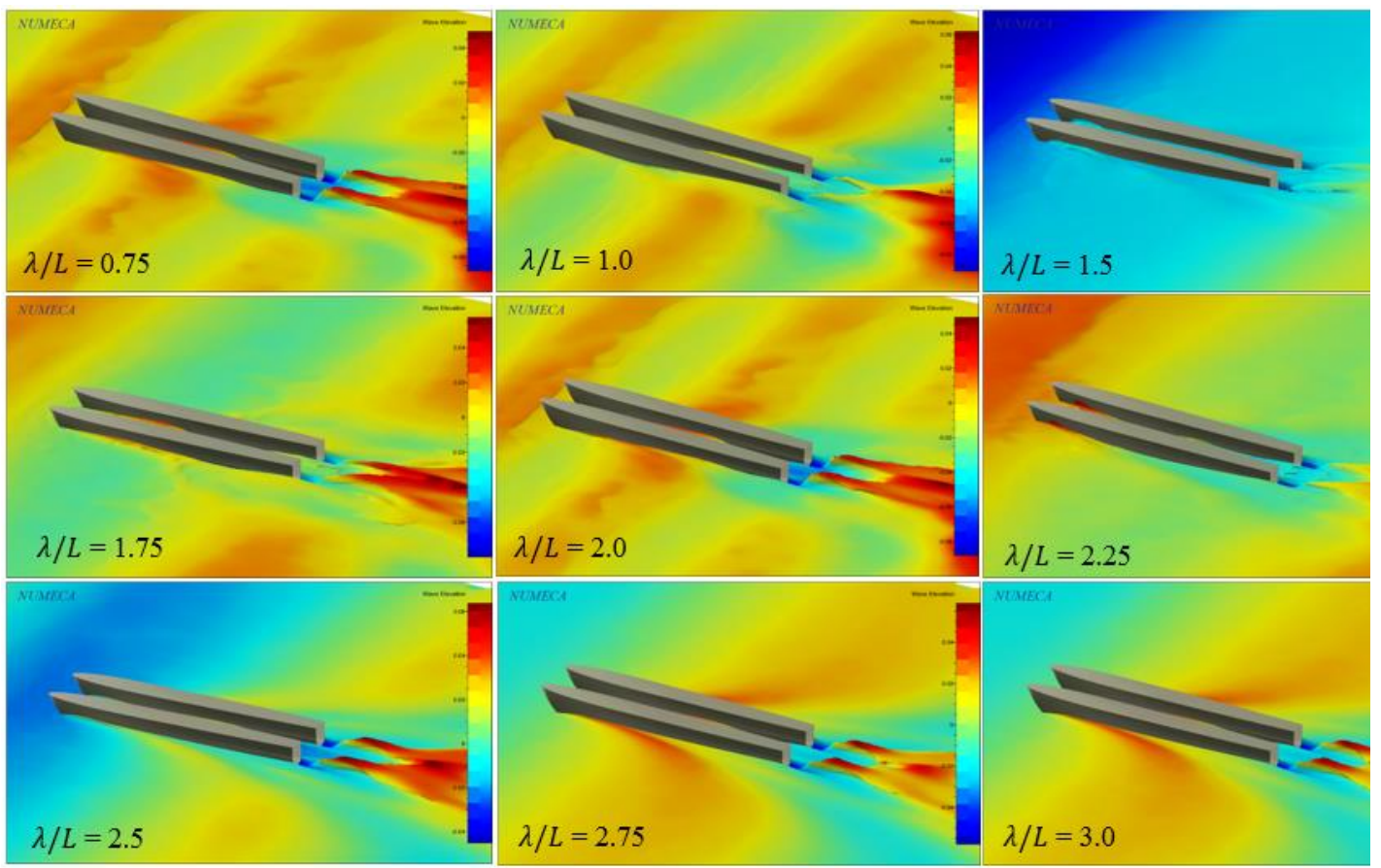

Figure 7. Wave pattern characteristics of catamaran at various wavelengths $(\lambda / L)$, $\mathrm{S} / \mathrm{L}=0.2, \mathrm{H}_{\mathrm{w}} / \mathrm{L}=0.027$ and $F r=0.47$
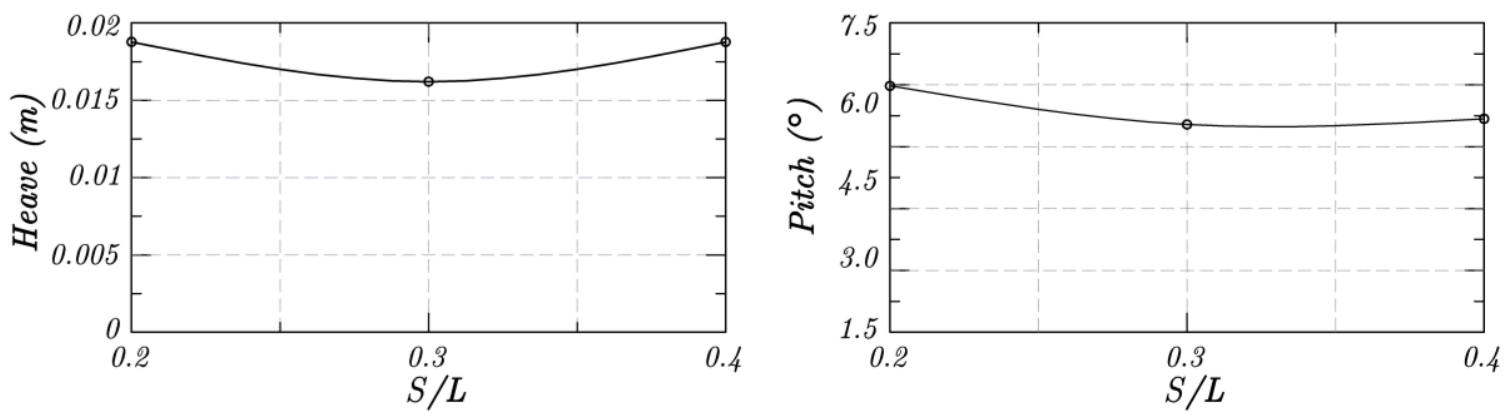

Figure 8. Heave and pitch motions behaviour at various $\mathrm{S} / \mathrm{L}$ ratios, $\lambda / \mathrm{L}=0.2, \mathrm{H}_{\mathrm{w}} / \mathrm{L}=0.027$ and $\mathrm{Fr}=0.47$

\section{Effect of Various Lateral Separation Ratios (S/L)}

Figure 8 shows the heave and pitch motions behaviour at various lateral separation ratios $(\mathrm{S} / \mathrm{L})$. Based on the results (see Table 6 ), the subsequent increase of the lateral separation ratios $(\mathrm{S} / \mathrm{L})$ from 0.2 to 0.3 had a moderate influence on the entire response amplitude motion performances of the catamaran. In general, this increment of S/L demonstrated a better seakeeping performance as indicated by the maximum reduction of the heave motions and pitch motions amplitude at about $13.8 \%$ and $12 \%$, respectively. Furthermore, the heave and pitch motions amplitude increased by $5.5 \%$ and $1.9 \%$ as the $\mathrm{S} / \mathrm{L}$ ratio increased from 0.3 to 0.4 . It can be concluded here that the amplitude of the heave and pitch motions of the rounded hull catamaran was relatively independent or even had a negligible and small influence with respect to that increment. Through wave pattern analysis at the increase of $\mathrm{S} / \mathrm{L}$ from 0.3 to 0.4 , the wave-making components consisting of pressure forces were prone to significantly 
reduce (see Figure 9). This means that the transverse waves from the bow travelled aft relative to the inner region between the two demi-hulls had not augmented yet. Even a significant wave crest (high wave amplitude) was susceptible to cancel out each other upon increasing the lateral separation ratios. This means that the increment of $\mathrm{S} / \mathrm{L}$ was becoming less obvious to the seakeeping performance of the rounded hull catamaran.

Table 6. Behaviour of heave and pitch motions at various ratios of S/L.

\begin{tabular}{ccc}
\hline S/L & Heave motion $(\mathrm{m})$ & Pitch motion $\left(^{\circ}\right)$ \\
\hline 0.2 & 0.0188 & 6.29 \\
0.3 & 0.0162 & 5.53 \\
0.4 & 0.0171 & 5.64 \\
\hline
\end{tabular}

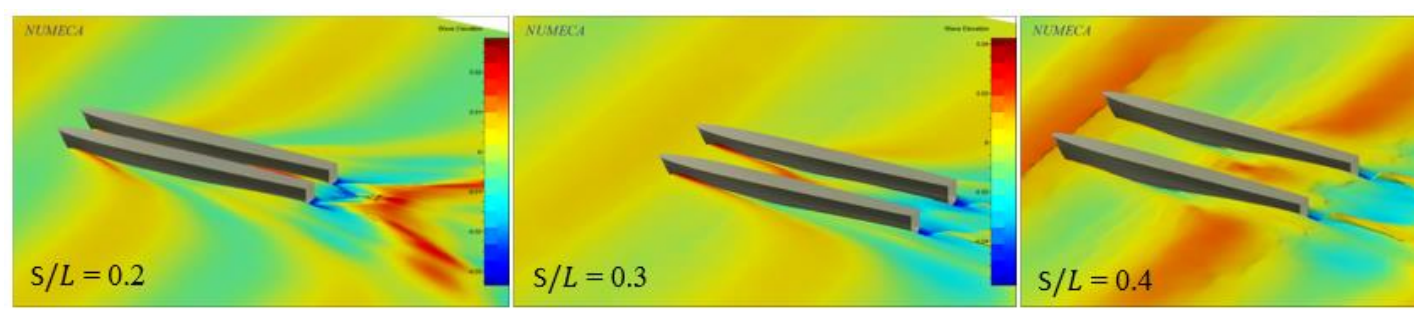

Figure 9. Wave pattern characteristics of catamaran at various lateral separation $\operatorname{ratios}(\mathrm{S} / \mathrm{L}), \lambda / \mathrm{L}=1.5, \mathrm{H}_{\mathrm{w}} / \mathrm{L}=0.027$ and $F r=0.47$.

\section{CONCLUSIONS}

The analysis of seakeeping performance of the rounded hull catamaran in waves was successfully carried out using computational fluid dynamic approach which is a valid tool in the simulation of seakeeping problems involving complex flow conditions. The computational simulations results are presented in the form of response amplitude operator, both of heave and pitch motions. Several parametric studies such as effects of Froude numbers, the lateral separation length ratio (S/L) and the ratios of wavelengths with respect to the length of catamaran $(\lambda / \mathrm{L})$ were taken into account. The computation results were drawn as follows:

i) The increase of Froude number up to 0.47 was proportional with the increase of the heave motions of the catamaran, where this condition was prone to degrade the seakeeping performance of the catamaran.

ii) In general, the rounded hull catamaran was liable to have vigorous vertical motion responses, both of the heave and pitch motions within the range of wavelength ratio with respect to the length of the catamaran $(1.5 \leq \lambda / L \leq 1.75)$. Consequently, these unfavorable motions led to the degradation of seakeeping qualities.

iii) The subsequent increase of the lateral separation ratios (S/L) from 0.2 to $0.3 \mathrm{had}$ a more moderate influence on the entire response amplitude motion performances of the catamaran as compared to the increase of S/L from 0.3 to 0.4 . It was noted that the maximum amount of the reduction for her heave and pitch motions were about $13.8 \%$ and $12 \%$, respectively as S/L increased from 0.2 to 0.3 , in which the seakeeping quality of the catamaran improved. 


\section{ACKNOWLEDGEMENTS}

The authors wish to thank the reviewers for their valuable comments and suggestions. Financial support from School of Ocean Engineering, Universiti Malaysia Terengganu is gratefully acknowledged.

\section{REFERENCES}

[1] Srinivas DV, Srinivas C. Design of catamaran ship strength deck to withstand the crane load. 2013.

[2] Medaković J, Ban D, Blagojević B. A comparison of hull resistances of a mono-hull and a swath craft. International Journal of Engineering, Science and Innovative Technology. 2013;2:155-62.

[3] Kenevissi F, Atlar M, Mesbahi E. A new-generation motion-control system for twin-hull vessels using a neural optimal controller. Marine Technology. 2003;40:168-80.

[4] Hadler J, Lee C, Birmingham J, Jones H. Ocean catamaran seakeeping design, based on the experiments of usns hayes. 1974.

[5] Piscopo V, Scamardella A. The overall motion sickness incidence applied to catamarans. International Journal of Naval Architecture and Ocean Engineering. 2015;7:655-69.

[6] Varyani KS, Gatiganti RM, Gerigk M. Motions and slamming impact on catamaran. Ocean Engineering. 2000;27:729-47.

[7] Rollings SE. Seakeeping analysis of small displacement high-speed vessels. Naval Postgraduate School Monterey Ca; 2003.

[8] Dyachkov V, Makov J. Seakeeping of a fast displacement catamaran. Transport. 2005;20:14-22.

[9] Kogan EM. To the hydrodinamical theory of oscillations of catamaran in liquid of finite depth. In: Proceedings of Nikolaev Shipbuilding Institute of adm SOMakarov Ship Theory. 1970;35:33-9.

[10] Kogan EM. To the calculation of main part of disturbance forces for oscillating catamaran in liquid of finite depth. In: Proceedings of Nikolaev Shipbuilding Institute of adm SOMakarov Ship Theory. Nikolaev: Shipbuilding Institute of adm. S.O.Makarov 1971. p. 42-5.

[11] Aimin D, Jun M. Study on prediction methodolo- gy of seakeeping for wpc. Chinese Journal of Ship Research. 2006;1:77-80.

[12] Guo ZQ, Ma QW, Yang JL. A seakeeping analysis method for a high-speed partial air cushion supported catamaran (PACSCAT). Ocean Engineering. 2015;110:357-76.

[13] Fang CC, Chan HS. Investigation of seakeeping characteristics of high-speed catamarans in waves. Journal of Marine Science and Technology. 2004;12:715.

[14] French B, Thomas G, Davis M, Holloway D. A high froude number timedomain strip theory for ship motion predictions in irregular waves. 18th Australasian fluid mechanics conference2012. p. 1-4.

[15] Han S, Lee YS, Choi YB. Hydrodynamic hull form optimization using parametric models. Journal of Marine Science and Technology. 2012;17:1-17. 
[16] Thomas G, Winkler S, Davis M, Holloway D, Matsubara S, Lavroff J, et al. Slam events of high-speed catamarans in irregular waves. Journal of Marine Science and Technology. 2011;16:8-21.

[17] Castiglione T, Stern F, Bova S, Kandasamy M. Numerical investigation of the seakeeping behavior of a catamaran advancing in regular head waves. Ocean Engineering. 2011;38:1806-22.

[18] Soars A. The hydrodynamic development of large wave piercing catamarans. 1993.

[19] Broglia R, Jacob B, Zaghi S, Stern F, Olivieri A. Experimental investigation of interference effects for high-speed catamarans. Ocean Engineering. 2014;76:75-85.

[20] Vakilabadi KA, Khedmati MR, Seif MS. Experimental study on heave and pitch motion characteristics of a wave-piercing trimaran. Transactions of FAMENA. 2014;38:13-26.

[21] Begovic E, Bertorello C, Pennino S. Experimental seakeeping assessment of a warped planing hull model series. Ocean Engineering. 2014;83:1-15.

[22] Bouscasse B, Broglia R, Stern F. Experimental investigation of a fast catamaran in head waves. Ocean Engineering. 2013;72:318-30.

[23] Kim DJ, Kim SY, You YJ, Rhee KP, Kim SH, Kim YG. Design of high-speed planing hulls for the improvement of resistance and seakeeping performance. International Journal of Naval Architecture and Ocean Engineering. 2013;5:161-77.

[24] Diez M, Broglia R, Durante D, Campana EF, Stern F. Validation of highfidelity uncertainty quantification of a high-speed catamaran in irregular waves. Proc 13th International Conference on Fast Sea Transportation, FAST2015. p. 1-4.

[25] Bruzzone D, Grasso A, Zotti I. Nonlinear seakeeping analysis of catamarans with central bulb. Proceedings of the 6th International Conference on HighPerformance Marine Vehicles Naples, Italy, 2008.

[26] Manual fine/marine: NUMECA International 2013.

[27] Menter F. Influence of freestream values on k-omega turbulence model predictions. AIAA Journal. 1992;30:1657-9.

[28] Menter F. Performances of popular turbulence models for attached and separated adverse pressure gradient flows. AIAA Journal. 1992b;30:2066-72.

[29] Menter F. Zonal two-equation $\mathrm{k}-\omega$ turbulence models for aerodynamic flows. AIAA 24th Fluid Dynamics Conference. 1993.

[30] Menter F. Two-equation eddy viscosity turbulence models for engineering applications. The American Institute of Aeronautics and Astronautics Journal. 1994a;32:1299-310.

[31] Spalart P, Allmaras S. A one-equation turbulence model for aerodynamic flows. 30th Aerospace Sciences Meeting and Exhibit. 1992:439.

[32] Baldwin B, Barth T. A one-equation turbulence transport model for high reynolds number wall-bounded flows. 29th Aerospace Sciences Meeting. 1991:610.

[33] Menter F, Rumsey C. Assessment of two-equation turbulence models for transonic flows. Fluid Dynamics Conference. 1994:2343.

[34] Fitriadhy A, Jamaluddin A, Norsani WM, Wan Nik WB, Bakar A, Azlan M, et al. Frictional resistance's prediction of a trimaran ship in calm water using computational fluid dynamic (CFD) approach. 2014. 
[35] Seif M, Mehdigholi H, Najafi A. Experimental and numerical modeling of the high speed planing vessel motion. Journal of Marine Engineering and Technology. 2014;13:62-72.

[36] Fitriadhy A, Lim PS, Jamaluddin A. CFD investigation on total resistance coefficient of symmetrical and staggered catamaran configurations through quantifying existence of an interference factor. In: The First International Conference on Ships and Offshore Structures ICSOS 2016. Hamburg, Germany; 2016. p. 1-20.

[37] Kim YC, Kim KS, Kim J, Kim Y, Park IR, Jang YH. Analysis of added resistance and seakeeping responses in head sea conditions for low-speed full ships using urans approach. International Journal of Naval Architecture and Ocean Engineering. 2017.

[38] Begovic E, Bertorello C, Pennino S, Piscopo V, Scamardella A. Statistical analysis of planing hull motions and accelerations in irregular head sea. Ocean Engineering. 2016;112:253-64.

\section{NOMENCLATURE}

CFD Computational Fluid Dynamic

RANSE Reynolds-Averaged Navier-Stokes Equations

QS Quasi-Static

ITTC International Towing Tank Conference

S/L Lateral Separation Ratio 